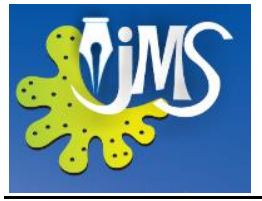

\title{
Perceptions and Attitudes among Venders towards Non-human Primates in Mihintale Wildlife Sanctuary in Sri Lanka
}

\author{
Kumara H.W.R. ${ }^{1 *}$, Nahallage C. A. D. ${ }^{1}$ and Huffman M. A. ${ }^{2}$ \\ ${ }^{1}$ Department of Anthropology, University of Sri Jayewardenepura, Sri Lanka \\ ${ }^{2}$ Department of Social Systems Evolution, Primate Research Institute, Kyoto University, Japan
}

\begin{abstract}
A number of studies have revealed that age, gender, ethnicity, level of education, political attitude, landholding size, period of residency and religion all influence attitudes towards wildlife. Attitudes also exhibit regional differences. However, religious beliefs of Sri Lankans and cultural practices play an important role when deciding the perceptions and attitudes toward primates. An important feature of this country is the presence of monkeys at Buddhist temples and archeological sites. Social and environmental conditions are deeply and inextricably linked, an important component of conservation, and the management of human-wildlife conflict, is therefore the examination of people's behaviour and perceptions regarding wildlife and the factors that influence these perceptions. This study was carried out in Mihintale wildlife Sanctuary in Anuradhapura district. To understand the nature of human attitude towards primates at the Mihintale wildlife sanctuary, the mixed methods approach was used for data collection. Interviews were conducted from April 2016 to September 2016. Direct interviews were conducted opportunistically with 57 venders in Sinhalese language to learn about macaques and langurs and their interactions with humans. The relationship with the venders and primates is complicated and filled with ambiguity. Venders are happy to see primates and other mammals in the wild, however, primates are not welcome near their business places. High population numbers and the inability to control monkeys are major concerns for venders. The nature of attitude onward each primate species depended on the level of interaction between humans and primate species. The attitude was negative toward the gray langurs and toque macaques, due to stealing of displayed toys, food items and the damage cause to the roofs of small shops, threatening venders and pilgrims when taking food by force. However, no negative attitude towards purple-faced leaf langurs. This study is important for conservation and for understanding the human perspective and attitude towards primates, when entwined with scientific evidence, offers a holistic understanding to one of the major problems in Sri Lanka, the human primate conflict.
\end{abstract}

KEYWORDS: Religious beliefs, Human-wildlife conflict, Primates, Perspective, Conservation 


\section{INTRODUCTION}

Values are the range of orientations towards an object that provide the foundation for an individual's attitudes, which in turn guides the interpretation and use of the object (Manfredo et al. 2003; Manfredo 2009). Not all values of nature are perceived by all people, and the reasons behind which values people hold, and therefore their perceptions and attitudes towards nature, are shaped by a multivariate role of intrinsic - individual experience and evolutionary, historic and extrinsic - economic, social and cultural - factors (Treves 2008). In ecological communities, primates play an important role and they are widely distributed across Africa, South America, South Asia, South-east Asia, Madagascar and Africa. Ecologically, Sri Lanka is an important island because of its high biodiversity. Sri Lanka is an important place to study primates because it is home to five species of primates (Dela, 2007; Rudran, 2007; Nahallage et al., 2008). These species include three catarrhines, the toque monkey (Macaca sinica), the purple faced leaf langur (Semnopithecus vetulus), the gray langur (Semnopithecus entellus) and two species of slender loris (Loris spp.). Mihintale wildlife Sanctuary, is named after the famous mountain peak 12 km east of Anuradhapura, an ancient city and former capital of the country, located $221 \mathrm{~km}$ north east of Colombo. Mihintale sanctuary is approximately 2470 acres (999.6 ha) in extent. Historical reasons make Mihintale a significant site for attracting religious and non-religious tourists. Mihintale is noteworthy as the world's oldest wildlife sanctuary, established more than 2200 years ago and human primate interactions have no doubt been going on from the beginning of the sanctuary's establishment, if not earlier when it was the hunting grounds of the King. Peoples' religious beliefs, folk beliefs and cultural context play an important role in defining the terms of human primate interactions and attitudes towards primates. Attitudes also show regional differences (Kellert 1997; Conover 1998). It is often the distance a person resides from a wildlife area that most strongly influences attitudes, with most people living closer to wild areas holding more negative views towards wildlife (Fiallo \& Jacobson 1995; Webber 2006; Nijman \& Nekaris 2010). Once again, this pattern is not universal (Naughton- Treves 1997), while other studies reveal no patterns at all (Heinen 1993; De Boer \& Baquete 1998). Livelihood affect attitudes towards wildlife. Those employed in wildlife-related fields display more positive attitudes towards wildlife (Fiallo \& Jacobson 1995), while agriculturalists hold more negative perceptions (Kellert 1997; Messmer 2000; Lindsey et al. 2005). A producer's economic dependence on a commodity also affects their attitude towards conflict and tolerance of wildlife (Wywialowski 1994; Jonker et al. 1998; Wang et al. 2006; Kirksey \& Helmreich 2010). The main objective of this study is to determine the attitudes among venders towards nonhuman primates; the toque macaque ( $\mathrm{M}$. sinica), purple-faced leaf langur (Semnopithecus vetulus philbricki) and crested gray langur (Semnopithecus priam thersites) at Mihintale wildlife sanctuary, North Central Province, Sri Lanka. The north central dry zone of Sri Lanka provided an ideal opportunity to study the attitude towards primates and interaction of these species with human. 


\section{METHODOLOGY}

To understand the nature of human attitude towards primates at the Mihintale wildlife sanctuary, the mixed methods approach was used for data collection. During the field visits a range of semi-structured interviews, focus groups discussion and participant observation was carried out. Data was collected from selected 57 members of permeant vendors (selling goods all throughout the year Mihinatle Archaeology site) by semi-structured interview. Purposive sampling technique was used to select interview subjects, appropriately given that the object of anthropological data collection was to identify the human attitude towards primates. This type of interview works well with busy people who require efficient use of their time such as vendors. Interviews were conducted from April 2016 to September 2016. Before collecting date using the interviews and discussions, the researcher had friendly chats with the community of vendors at the Mihintale archeological site. This allowed interviewees to feel more comfortable answering the questions regarding the real situation of human primate conflict at Mihintale. Interviews were conducted at the informants' shops as a non-threatening, relaxing environment for them. Interviews were conducted on voluntary basis without monetary reward and in the major local language Sinhalese. Each interview lasted around 45 minutes, depending on the participant's willingness to talk, and on how knowledgeable and in depth their answers were. To understand the attitude and perceptions towards primates, 10 item questionnaires in Sinhalese was prepared. Fifty-seven interviews were conducted, all permanent vendors. A total of $57(n=57)$ of sellers were interviewed that included, fruit sellers $21.1 \%(n=12)$, flower sellers $17.5 \%$ $(n=10)$, sweet and food sellers $24.6 \%$ $(n=14)$, Toys sellers $22.8 \%(n=13)$, others sellers $14 \%(n=8)$. The focus of the data collection is on sellers. Participation observation method was used to gather information into the daily lives of the local vendors and built trustful relationships with pilgrims to observe human primate conflict, attitudes and their reaction to primates. All events of conflict between primates and humans were recorded during the field study.

\section{RESULT AND DISCUSSION}

Direct interviews with individuals were conducted opportunistically in local language to learn about macaques and langurs and their interactions with humans. Out of 57 vendors interviewed 36 vendors were selling edible goods which included fruits, food, sweets and flowers (consume by monkeys); 21 venders were selling nonedible goods like toys and garment items, pottery etc. All venders interviewed were Sinhalese Buddhist including 33 males and 24 females. The education level ranges from grade 2 to advance level. Their age range is 16 to 73 years. No of the vendors had permanent buildings, all were temporarily made shops which were covered with polythene, wood or sheets. There were no proper walls, doors or winders to protect goods from monkeys. Some shops did not have proper roofs as well. Monkeys could enter to shops from any sides.

Almost all of the interviewees (venders in Mihinale) considered themselves Buddhist and in line with the tenets of this religion there was a high level of tolerance towards 
primates. One fundamental influence on perceptions of primates is the general and their activities. In Buddhism, it is prohibited to kill animals and to threaten them. Culture is one of the main values that always puts distance between animals and humans, and it also determines the rights of animals in each culture. Levels of tolerance, acceptance and even demand for interactions vary across cultures (Biquand et al., 1992; Burton, 2002; Gautier \& Biquand, 1994, Nahallage, et. al., 2008, Nahallage and Huffman, 2013). Attitudes are defined as the evaluation of a particular object with some degree of favour or disfavour (Allendorf 2007), attitudes towards nature however cannot simply be described as positive or negative. People's relationships with nature are far more complicated and emotional. Buddhists and Hindus has many religious values for primates.

As such, attitudes and beliefs towards nature are complex and can change over time, in association with changing conditions and experiences (Hill 2002). They can also shift rapidly with any stressor, such as drought, famine, land disputes or local politics (Lee 2010). In order to understand which values are adopted and why different people adopt different values, we need to understand the beliefs and motivations behind these values. When asked what they think about nature in Mihintale area, every interviewee responded positively with statements such as 'I love it', 'it's wonderful', and its peaceful (100\%). However, alongside these positive statements sellers also express negative sentiments towards the same wildlife. Because of human primate conflict, ( $n=54)$ 94.7\% interviewee express negative statement on primates and only $(n=3) \quad 5.3 \%$ had positive statement. cultural attitude of people towards primates

Nonhuman primates were viewed as brethren and this has enabled their survival throughout much of Asia. In parts of Northern India, Indonesia, and other areas, monkeys are worshipped, protected and provisioned by villagers (Southwick \& Siddiqi, 1977). In Sri Lanka, the peoples' religious beliefs and cultural practices play an important role in defining the terms of primate-human interactions and reflect the past, present, and potential future of their coexistence. An important feature of this country is the presence of monkeys at Buddhist and Hindu temples (Nahallage et al., 2008; Nahallage and Huffman, 2013). Furthermore, the venders who had negative attitude to primate, did not had any negative attitude on any other wild animals. Even at this point in the interview, $77.8 \%$ participants had $(\mathrm{n}=42)$ negative connotations towards toque macaque and $22.2 \%(n=12)$ on gray langurs, no $(n=0)$ negative connotations toward purple-faced leaf langur. Attitudes among venders differ according to primate species involved. The negative or positive attitude to each species of primates depend on the intensity of the human primate conflict. According to both observations and interviews, only two species (S. priam thersites and M. sinica) had been involved in the human primate conflict at Mihintale. The $S$. vetulus philbricki was not involved in human primate conflict. The constant supply of food offerings given to them by religious followers and tourists keep macaques and langurs around the temple grounds.

Interviewees had positive connotations to the intelligence of toque macaque intelligence and it was said to be the reason to have more conflict with toque macaques than the two langur species. The other fact 
that revealed in the interview was toque macaques prefer human food more than natural food $43.9 \%(n=25)$, toque macaque are more astute than the two langurs $56.1 \%$ because of their skills, which are like those of humans". Thus, villages are more aggressive toward the toque macaques and gray langur, but the purple- faced leaf langur was considered as a gentle creature. According to interviews conducted majority of the respondents had negative (94.7\%) attitudes towards primates, very few people (5.3\%) had positive statements about primates in Mihintale. Even though the majority of venders in the park had an overall negative perception toward primates, they also appreciate primates for variety of reasons. These included "Monkeys can attract tourists to Mihintale and that is our county's main income", "I enjoy watching the monkeys", "it's attractive", "to disturb or harm them is not good according to our religion". The percentage of people with negative attitudes for each species varies; $M$. sinica $77.8 \%, S$. priam thersites $22.2 \%$ and $S$. vetulus $0 \%$. No one had negative attitude towards $S$. vetulus. Many venders noted that $\mathrm{M}$. sinica is the "most intelligent and astute monkey" at Mihintale, while $S$. vetulus is "the most innocent monkey and are gentle creatures", "villagers are more aggressive toward $M$ sinica and $S$. priam theresites" at Mihintale. Only one vender said that "Mihintale is the oldest sanctuary in the world and there were monkeys here from the beginning, so they have the right more than us to live here, because those rights were given to them by King Devanampiyatissa when he established this The findings of this study is important as a conservation tool for understanding the human perspective and attitudes towards primates, which, when entwined with $(n=32)$. Number of venders discourse about the close similarity between humans and $t$ both macaque and langurs. Local venders in Mihintale claim "Monkeys are a problem sanctuary, we are the party who is violating the right of the monkeys not actually the animals". Sri Lankans believe Mihinthale to be the place where the first meeting took place between Mahinda thero (the son of King Ashoka from India), and King Devanampiyatissa (from 307 to 267 BC) the ruler of Sri Lanka at the time. This meeting is said to have brought about the acceptance of Buddhism into Sri Lanka (Mahawamsaya) by the decree of King Deanampiyatissa. The people's perception of the human-primate conflict in Mihintale depends on the species and the amount of damage caused by them. Like Anuradhapura, there are many large and small Buddhist temples across the country where primates are protected by the peoples' religious and cultural beliefs (Nahallage and Huffman, 2013). In Sri Lankan cultural context, the religions are playing a significant role in controlling and suppressing human primate conflict. Primates can symbolize human's bestiality or dubious morality, possibly due to their obvious morphological similarity to humans (Knight, 1999; Morris \& Morris, 1966). The causal factors of conflict between human and nonhuman primates assume special significance (Dickman, 2012; Fuentes, 2012) as humans and nonhuman primates have shared ecological space over millennia (Fuentes \& Wolfe, 2002; Fuentes, 2012, Nahallage, 2019).

\section{CONCLUTION}

scientific evidence, offers a holistic understanding to one of the major problems in Sri Lanka, the human primate conflict. 


\section{REFERENCES}

Allendorf, T., (2007). Residents' attitudes toward three protected areas in southwestern Nepal. Biodiversity and Conservation, 16(7), pp.2087-2102.

Biquand S, Biquand-Guyot V, Boug A., \& Gautier J-P. (1992). The distribution of Papio hamadryas in Saudi Arabia: ecological correlates and human influence. International Journal of Primatology 13(3), 223-243.

Conover, M.R., (1979). Response of birds to raptor models. Proceedings of the Bird Control Seminar, 4, 16-24.

Dela, J. (2007). Seasonal food use strategies of Semnopithecus vetulus nestor, at Panadura and Piliyandala, Sri Lanka. International Journal of Primatology, 28, 607-626

Dickman, A. (2012). From cheetahs to chimpanzees: a comparative review of the drivers of human-carnivore conflict and human-primate conflict. Folia Primatologica, 83(6), 377-387.

Fiallo, E.A. \& Jacobson, S.K., (1995). Local communities and protected areas: attitudes of rural residents towards conservation and Machalilla National Park, Ecuador. Environmental Conservation, 22(03), p.241-249.

Fiallo, E.A., \& Jacobson, S.K. (1995). Local communities and protected areas: attitudes of rural residents towards conservation and Machalilla National Park, Ecuador. Environmental Conservation, 22(03), 241-249.

Fuentes, A., \& Wolfe, L.D. (2002). Primates face to face: the conservation implications of human-nonhuman primate interconnections. Cambridge: Cambridge University Press.

Fuentes, A., (2006). Human-nonhuman primate interconnections and their relevance to anthropology. Ecological and Environmental Anthropology, 2(2), pp.111.

Geiger, W. (1934). The Mahawamsa (The Great Chronicle of Ceylon-Sri Lanka) Oxford University Press London.

Hill, C.M., (2002). Primate conservation and local communities - ethical issues and debates. American Anthropologist, 104(4), pp.1184-1194.

Jonker, S.A., Parkhurst, J.A., Field, R. \& Fuller, T.K., (1998). Black bear depredation on agricultural commodities in

Massachusetts. Wildlife Society Bulletin, 26(2), pp.318-324.

Kellert, S.R., (1997). The Value of Life: Biological Diversity and Human Society, Washington, DC: Island Press.

Kirksey, S.E. \& Helmreich, S., (2010). The emergence of multispecies ethnography. Cultural Anthropology, 25(4), pp.545-576.

Kirksey, S.E. \& Helmreich, S., (2010). The emergence of multispecies ethnography. Cultural Anthropology, 25(4), pp.545-576.

Knight J. (1999). Monkeys of the move: the natural symbolism of people-macaque conflict in Japan. J Asian Stud, 58(3):622647.

Lee, P.C., (2010). Sharing space: can ethnoprimatology contribute to the survival of nonhuman primates in human-dominated globalized landscapes? American journal of primatology, 72(10), pp.925-31. 
Lindsey, P. A., Du Toit, J.T. \& Mills, M.G.L., (2005). Attitudes of ranchers towards African wild dogs Lycaon pictus: conservation implications on private land. Biological Conservation, 125(1), pp.113121.

Manfredo, M. M. (2004). Concepts for exploring the social aspects of humanwildlife conflict in a global context. Human Dimensions of Wildlife, 9(4), 1-20.

Manfredo, M.J., (2009). Who Cares About Wildlife?: Social Science Concepts for Exploring Human- Wildlife Relationships and Conservation Issues, Springer Science \& Business Media.

Manfredo, M.J., Teel, T. \& Bright, A., (2003). Why are public values toward wildlife changing? Human Dimensions of Wildlife, 8(4), pp.287-306.

Messmer, T. (2000). The emergence of human-wildlife conflict management: turning challenges into opportunities. International Biodeterioration \& Biodegradation, 45(3), 97-102.

Nahallage, C.A.D., Huffman, M.A., Kuruppu, N. and Weerasingha, T. (2008). Diurnal Primates in Sri Lanka and People's Perception of Them. Primate Conservation, 23(1), 81-87.

Nahallage, C.A.D. \& Huffman, M.A. (2013). Macaque - Human interactions in Past and Present day in Sri Lanka. In S. Radhakrishna, M. A. Huffman \& A. Singha (Eds.), Macaque Connections: Corporation and Conflict between Humans and Macaques (pp. 135 -148). Springer Publication.

Nahallage, C.A.D. (2019). An Ethnoprimatological Perspective of Human
Primate Interactions: The Sri Lankan

Context. Vidyodaya Current Research, 1(1), $27-37$.

Naughton-Treves, L., (1997). Farming the forest edge: vulnerable places and people around Kibale National Park, Uganda. The Geographical Review, 87(1), pp.27-46.

Nijman, V., \& Nekaris, K.A.I. (2010). Effects of deforestation on attitudes and levels of tolerance towards commensal primates (Cercopithecidae) in Sri Lanka. International journal of pest management, 56(2), 153-158.

Rudran, R. (2007). A survey of Sri Lanka's Endangered and endemic Western purplefaced langur (Trachypithecus vetulus nestor). Primate Conservation, (22), 139144.

Treves, A., (2008). The human dimensions of conflicts with wildlife around protected areas. In Manfredo, M.J., Vaske, J.J., Brown, D.J., Decker, D.J. \& Duke, E.A., eds. Wildlife and Society: The Science of Human Dimensions. Washington, DC: Island Press, pp. 214-228.

Wang, S.W., Curtis, P.D. \& Lassoie, J.P., (2006). Farmer perceptions of crop damage by wildlife in Jigme Singye Wangchuck

National Park, Bhutan. Wildlife Society Bulletin, 34(2), pp.359- 365.

Webber, A.D., (2006). Primate crop raiding in Uganda: actual and perceived risks around Budongo Forest Reserve. PhD, Oxford Brookes University.

Wywialowski, A.P., (1994). Agricultural producers' perceptions of wildlife-caused losses. Wildlife Society BulletinSociety, 22(3), pp.370-382. 